\title{
Detecting Rotor Asymmetries with Variable Speed Drive at Standstill
}

\author{
Jordi Burriel-Valencia, Manuel Pineda-Sanchez, Juan Perez-Cruz, Martin V. Riera-Guasp, Ruben Puche-Panadero
}

\begin{abstract}
The diagnosis of Induction Motors (IMs) is crucial to avoid unexpected economic losses due to their failures. To reduce the cost associated to its maintenance, a recent trend is the integration of diagnostic procedures in the electronic equipment that control the motor, such as variable speed drives (VSD)s. This paper presents a new methodology to detect rotor asymmetries and unbalanced contact resistances in IMs fed from VSDs, at standstill. The proposed approach is a non-invasive technique, can be executed on-line, and is not expensive because this method does not need extra hardware or additional sensors. Besides, the results of the proposed diagnostic method are presented in a very graphical and easy to understand way, alike to a dartboard, which makes it easily understandable by non-qualified personal maintenance. The proposed methodology is validated experimentally with a commercial induction motor with different rotors, both healthy and faulty.
\end{abstract}

Index Terms-Induction machines, fault diagnosis, condition monitoring, motor current signature analysis, digital signal processor (DSP), field programmable gate array (FPGA), broken rotor bar

\section{INTRODUCTION}

The reliability, robustness, low maintenance requirements, and the advances in power electronics have made cage IMs the horsepower in the electromechanical energy conversion in modern industrial installations. Despite its robustness, these machines are not free from suffering failures that may lead to huge economic losses, well beyond the cost of the motor itself. Hence, to avoid unexpected outages, it is crucial to detect the faults at an early stage, before the breakdown of the motor. Among the possible methods and techniques used in the technical literature, the analysis of the current, or motor current signature analysis (MCSA), has become an important method to diagnose the IMs due to its advantages: it is a non-invasive method, and it has low requirements on software and hardware, among others. Besides, each fault generates or amplifies a set of harmonic components on the stator current whose frequencies have been determined theoretically. For example, in case of rotor asymmetries, the harmonic fault components generate frequencies $f_{b b}[1]$

$$
f_{b b}=f_{\text {mains }} \cdot(1+2 k s) \quad k= \pm 1, \pm 2, \pm 3 \ldots,
$$

This work was supported by the Spanish "Ministerio de Economía y Competitividad" in the framework of the "Programa Estatal de Investigación, Desarrollo e Innovación Orientada a los Retos de la Sociedad" (project reference DPI2014-60881-R).

The authors are with the Department of Electrical Engineering, Universitat Politècnica de València, Valencia, Spain where fmains is the frequency of the power supply and $s$ is the slip. In case, of mixed eccentricity, the frequencies of the fault components $f_{\text {ecc }}$ are

$$
f_{\text {ecc }}=f_{\text {mains }}+2 k f_{r} \quad k= \pm 1, \pm 2, \pm 3 \ldots,
$$

where $f_{r}$ is the mechanical speed of the rotor.

Although MCSA has proved its validity for detecting faults in IMs, there are still a several drawbacks: the Fourier analysis needed to track the harmonic components generated by each fault, according to (1) or (2), is restricted to IM working in steady state conditions. Besides, an accurate speed (or slip) measurement is required to compute these frequencies. Several techniques have been proposed recently to analyze the stator current in transient regime, such as the start-up transient of IM, but this requires complex signal processing tools and costly devices, which limits its industrial deployment.

On-line fault diagnosis techniques have attracted a rising interest [2], [3]. They monitor continuously the IM checking it condition. Several on-line fault diagnosis methods have been proposed to be implemented in low cost devices such as digital signal processor (DSP) [4], field programmable gate array (FPGA) [5]-[7] or more recently general-purpose graphics processing unit (GPGPU) [8]. However, from the industrial point of view, there are still several drawbacks for the massive use of this devices for fault diagnosis. High sampling frequencies, used to avoid the aliasing distortions, along with long acquisition times, to obtain high spectral resolution, generate a huge amount of data which is difficult to be processed using these devices. Moreover, complex signal processing tools to detect faults in IMs working in transient regime need high power computing requirements. Hence, the diagnostic procedure must be simple, compact and fast, to be executed on-line by embedded devices [9]-[11]. Doubtlessly, the ideal would be the implementation of the fault diagnosis methods in the same equipment that controls the IM, such as variable speed drive (VSD), giving an added value to this equipment.

In this paper, a new diagnostic method is proposed to address these problems, which is simple, fast and with low hardware and software requirements to be implemented in low cost devices, even in the VSDs that feeds the IMs. This method follow the methodology proposed in [12], [13] for detecting the high-resistance connection asymmetries in inverter-fed IMs, and extends it to the detection of rotor asymmetries, such as broken bar faults. For the validation of this methodology different rotors are used, both in healthy and faulty condition. An added feature of the proposed method is that the motor condition is displayed to the operator using an industrial-grade 
human-machine interface (HMI), in a very easy to understand graphical display.

The structure of this paper is as follows: the methodology of the proposed method is presented in Section II. In Section III the test bench is described. In Section IV the experimental results are presented, and, finally, in Section $\mathrm{V}$ the conclusions of this work are presented.

\section{Methodology}

The methodology followed in this work is very simple and easy to apply from the point of view of a variable speed drive (VSD). The proposed methodology is based on the measurement of the current at standstill, when the IM is fed using only two of its three terminals. Three measurements are made. In a first step the phases A and B of the machine are fed, using half of its rated voltage in order to limit the phase current, I Iest 1 . Next, the machine is fed using phases B and C, obtaining the current $I_{\text {test }}$. Finally, the third step consist on feeding the phases $\mathrm{C}$ and $\mathrm{A}$, and the resulting current Itest3 is obtained. This measurement sequence can be easily programmed in the VSD that supplies the machine.

When the motor is fed using only two terminals, that is, with the same current (but in opposite directions) in two of the motor windings (and no current in the other one), the magnetic field generated by this current is an alternating one, but its spatial position is fixed and does not rotate. So changing the sequence of the two phases that are fed, following the procedure described before, changes the position of the resulting field in the motor air gap (see Fig. 1).

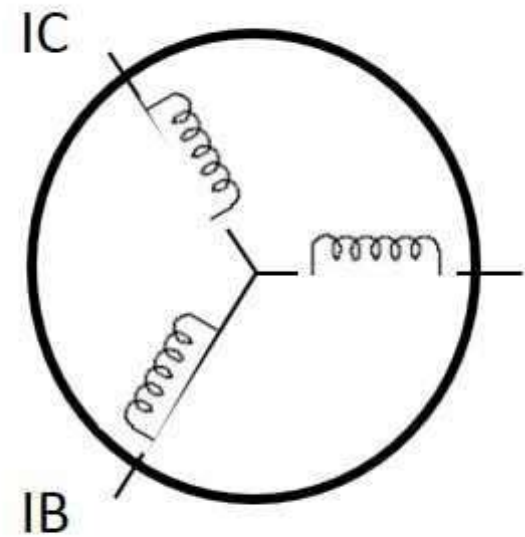

Fig. 1. Scheme of the electrical machine reduced winding.

In a healthy machine, the three currents obtained in the tests $\left(I_{\text {test }}, I_{\text {test } 2}, I_{\text {test } 3}\right)$ should be quite similar, but in a faulty machine there will be a significant difference between them, depending on the location of the faulty rotor in the stator reference frame. To detect this difference, a current vector is built, with $x-y$ components given by (3) and (4).

$$
\begin{gathered}
I_{x}=I_{t e s t 1}-\left(I_{t e s t 2}+I_{t e s t 3}\right) \cdot \cos (\pi / 3) \\
I_{y}=\left(I_{t e s t 2}-I_{t e s t 3}\right) \cdot \sin (\pi / 3)
\end{gathered}
$$

The representation of the point with coordinates (3) and (4) coincides with the origin if the machine is in healthy condition, so that the three currents $\left(I_{\text {test } 1}, I_{\text {test } 2}, I_{\text {test } 3}\right)$ are balanced. But, if the motor has a rotor asymmetry, or the contact resistance at the motor terminals is unbalanced, this point is displaced, being its distance from the origin a clear indication of the fault.

\section{TEST BED}

For validating the proposed methodology, a commercial VSD is used, and the diagnostic algorithm has been run on a personal computer, to verify it. This algorithm is simple enough to be implemented in the VSD microcontroller or DSP.

The scheme of the test bed is shown in Fig. 2 and the real test bed is shown in Fig. 3.

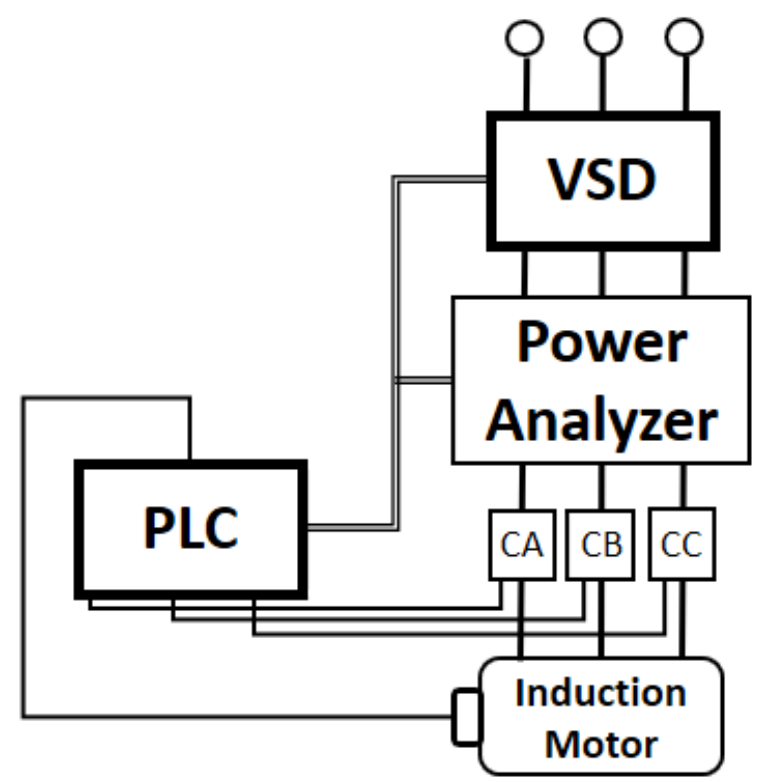

Fig. 2. Schematic diagram of the test bed.

Three motors, whose characteristics are given in Appendix A, have been used for the experimental validation: a healthy IM, and two faulty IMs, one with two broken bars, and the other one with four broken bars (see Fig. 4). To keep the rest of conditions of the different tests unaltered, the same stator has been used with the three tested rotors.

The IM under test is fed from a VSD. In order to do the tests automatically, a programmable logic controller (PLC) is used to manage the sequence of the test. Between the VSD and the IM, the measurement equipment, a power analyzer, has been inserted. Besides, a single-phase contactor in series with each phase of the motor is used to configure the topology of the circuit (two phases connected and the other one disconnected) during each test. 
Proc. of the International Conference on Advances in Mechanical and Automation Engineering - MAE 2016

Copyright (C) Institute of Research Engineers and Doctors. All rights reserved.

ISBN: 978-1-63248-102-3 doi: 10.15224/ 978-1-63248-102-3-72

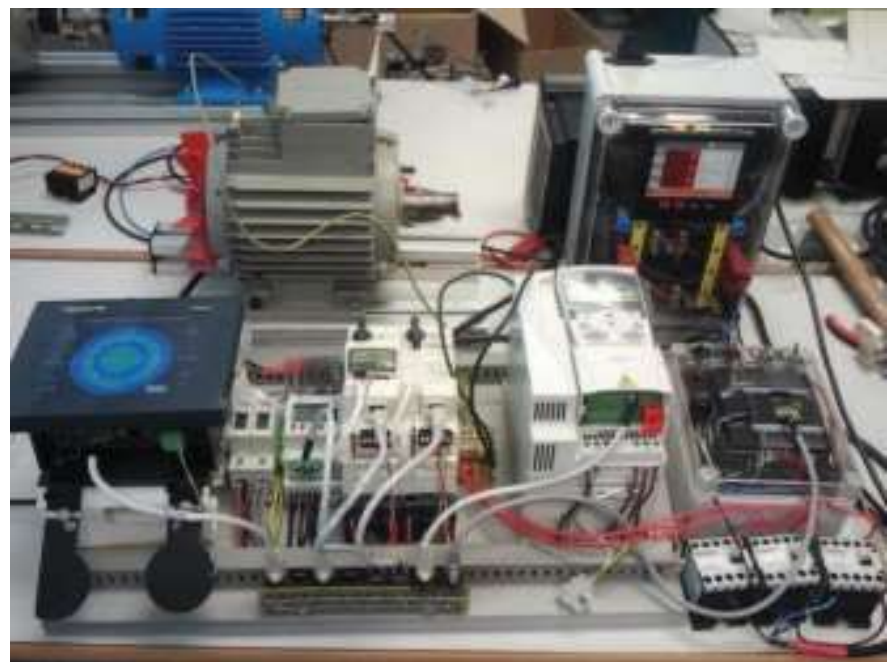

Fig. 3. Picture of the test bed.

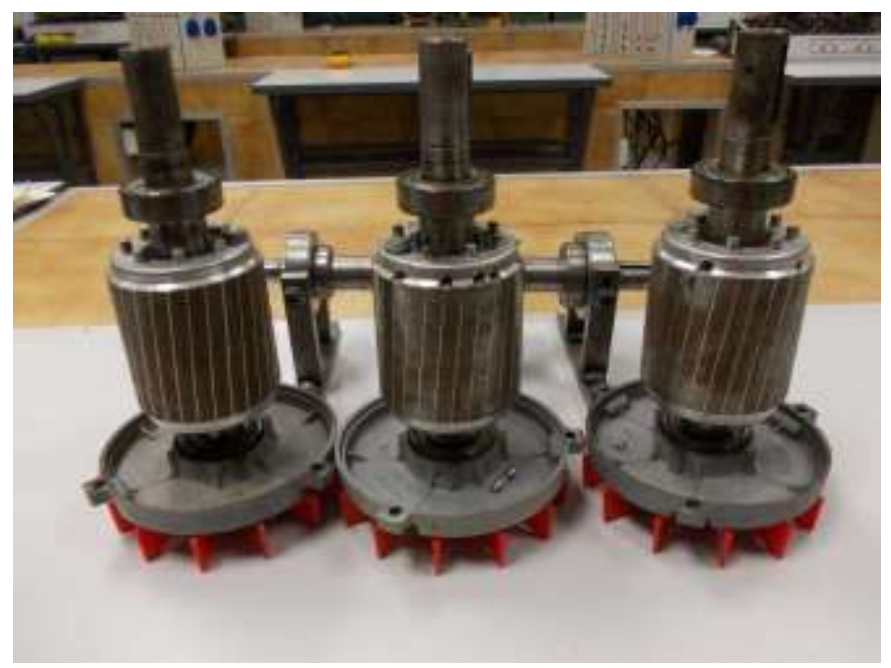

Fig. 4. Picture of the three rotors tested; healthy motor (left), motor with four broken bars (center), and motor with two broken bars (right).

The PLC is connected to the VSD and to the power analyzer using a Modbus industrial network. Besides, a touch panel (HMI), which is connected to the Modbus lines, is used to display on-line the results and to plot the points given by (3) and (4) at each test Fig. 5. The touch panel allows to know in "situ" and in real time the machine condition.

For each test, the PLC sends the reference frequency to the converter and the run/stop command, via Modbus, and reads the phase currents from the power analyzer. Moreover, the PLC acts over the digital outputs to connect the singlephase contactors, according to the sequence of each test. The VSD is parametrized with a scalar control with programmable characteristic voltage/frequency (linear but with the voltage limited to half the value of the rated voltage, in order to protect the motor).

For increasing the reliability of this new approach the three tests are repeated at different rotor positions, each 30 mechanical degrees in this work.

Fig. 6 shows a general view of the test bed setup.

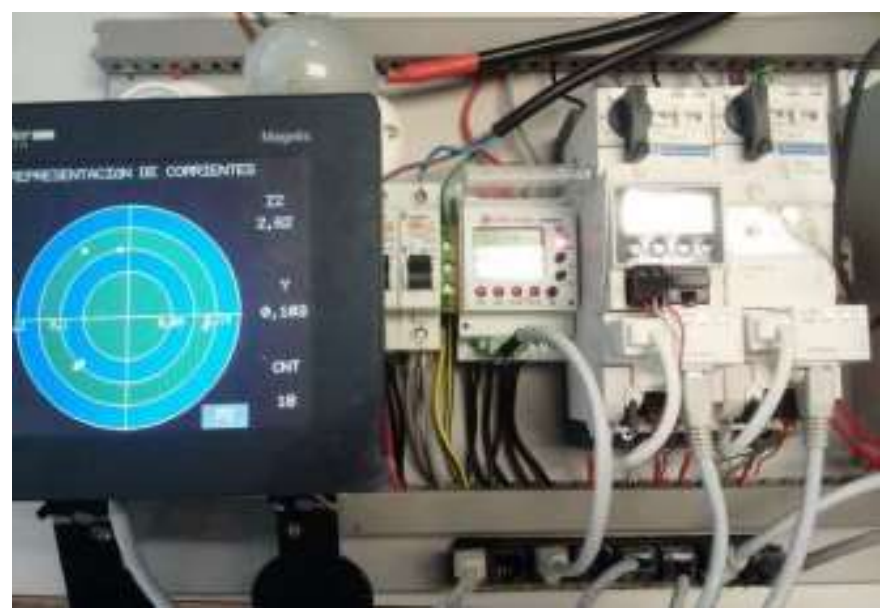

Fig. 5. Representation in the dartboard of the HMI from the two broken bar motor.

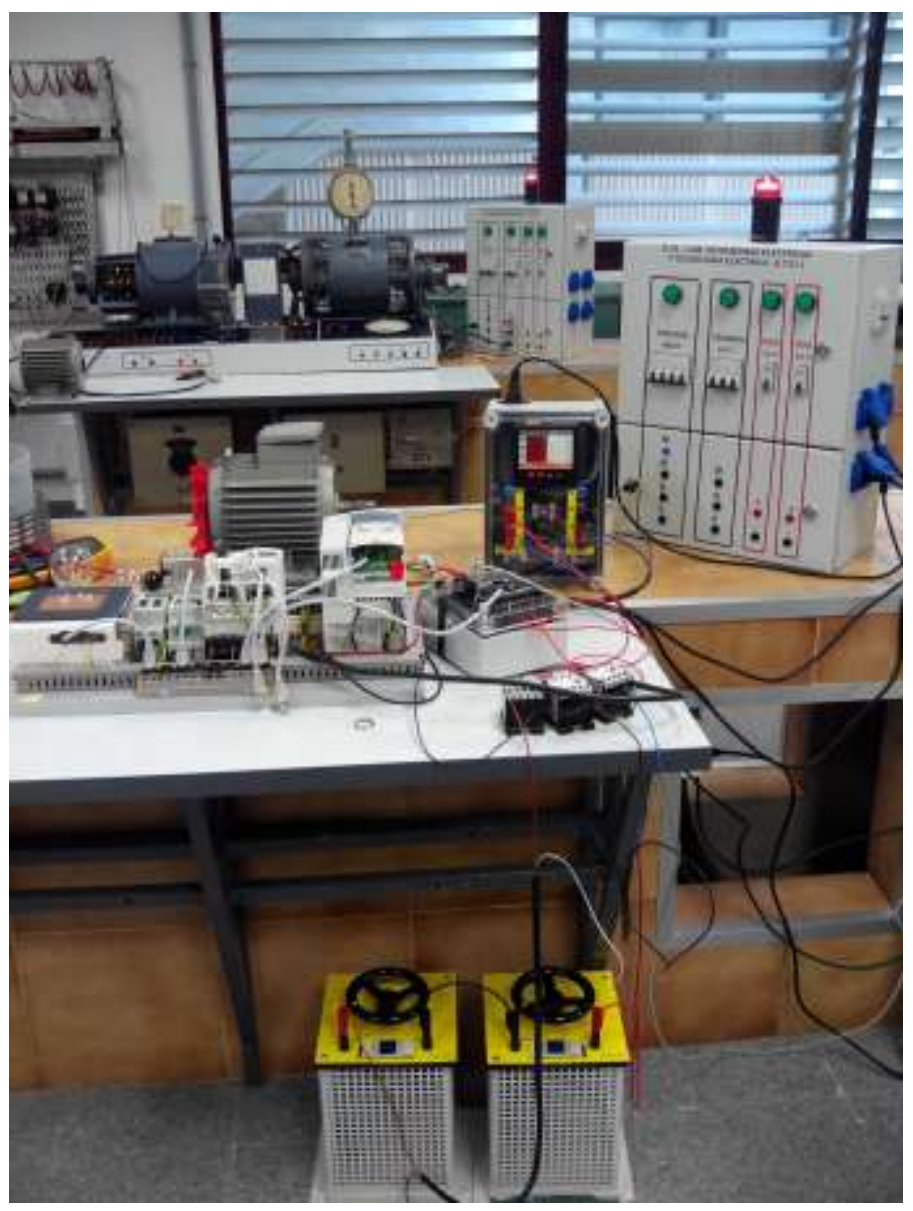

Fig. 6. General view of the test bed used for the experimental validation of the proposed method.

\section{RESULTS}

Table I presents the results obtained with the healthy motor, using twelve measurements made at every 30 degrees of the rotor angular position. In an industrial environment, where there is no possibility of fixing the position of the rotor, the measurements can be taken at different motor stops, which should give different rotor angular positions after it stops. 
TABLE I

TEST OF THE MOTOR IN HEALTHY CONDITION

\begin{tabular}{ccccc}
\hline \hline Degrees & Voltage (V) & \multicolumn{3}{c}{ Current (A) } \\
& & Test1 & Test2 & Test3 \\
\hline 0 & 115 & 2.34 & 2.34 & 2.35 \\
\hline 30 & 115 & 2.34 & 2.34 & 2.35 \\
\hline 60 & 115 & 2.32 & 2.33 & 2.34 \\
\hline 90 & 115 & 2.32 & 2.32 & 2.34 \\
\hline 120 & 115 & 2.31 & 2.31 & 2.34 \\
\hline 150 & 115 & 2.30 & 2.31 & 2.32 \\
\hline 180 & 115 & 2.30 & 2.30 & 2.32 \\
\hline 210 & 115 & 2.30 & 2.30 & 2.32 \\
\hline 240 & 115 & 2.31 & 2.30 & 2.32 \\
\hline 270 & 115 & 2.28 & 2.29 & 2.30 \\
\hline 300 & 115 & 2.29 & 2.29 & 2.32 \\
\hline 330 & 115 & 2.29 & 2.28 & 2.31 \\
\hline
\end{tabular}

TABLE II

TEST OF THE MOTOR WITH TWO BROKEN BARS

\begin{tabular}{ccccc}
\hline \hline Degrees & Voltage (V) & \multicolumn{3}{c}{ Current (A) } \\
& & Test1 & Test2 & Test3 \\
\hline 0 & 115 & 2.60 & 2.73 & 2.63 \\
\hline 30 & 115 & 2.62 & 2.60 & 2.73 \\
\hline 60 & 115 & 2.71 & 2.62 & 2.60 \\
\hline 90 & 115 & 2.59 & 2.71 & 2.63 \\
\hline 120 & 115 & 2.60 & 2.59 & 2.72 \\
\hline 150 & 115 & 2.70 & 2.60 & 2.60 \\
\hline 180 & 115 & 2.57 & 2.70 & 2.60 \\
\hline 210 & 115 & 2.59 & 2.57 & 2.70 \\
\hline 240 & 115 & 2.67 & 2.60 & 2.58 \\
\hline 270 & 115 & 2.55 & 2.68 & 2.60 \\
\hline 300 & 115 & 2.59 & 2.56 & 2.68 \\
\hline 330 & 115 & 2.69 & 2.61 & 2.60
\end{tabular}

The results from Table I are represented alike a dart board in Fig. 7. All of the samples are close to the zero point of the dartboard because the currents are balanced. These results confirm that the machine is in a healthy condition.

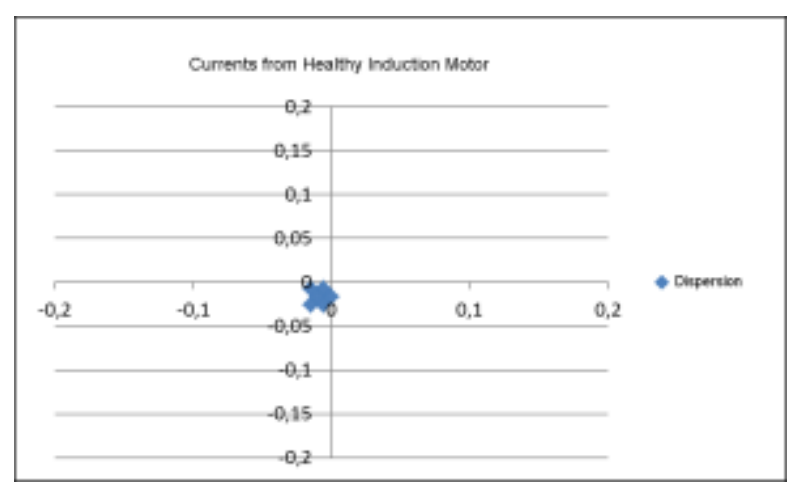

Fig. 7. Representation in the dartboard of the results for the healthy motor.

Table II presents the same results as Table I, but obtained with the motor with two broken bars.
The results from Table II are represented as a dart board in the Fig. 8. All of the samples are located far way of the zero point of the dartboard, because the currents are not balanced, which means that the machine is in faulty state.

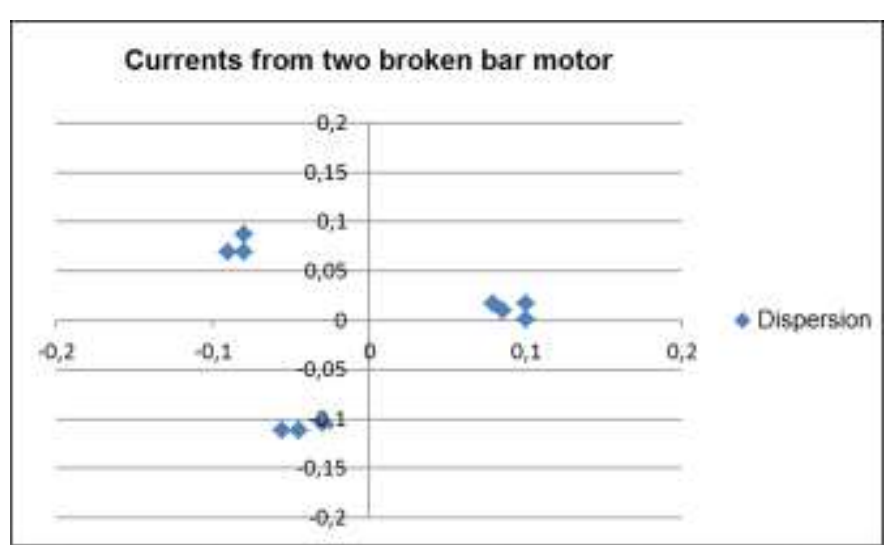

Fig. 8. Representation in the dartboard of the results for the motor with two broken bars

Finally, the results obtained with the tests of the motor with four broken rotor bar are shown in Table III, and depicted in Fig. 9.

\section{Currents from four broken bar motor}

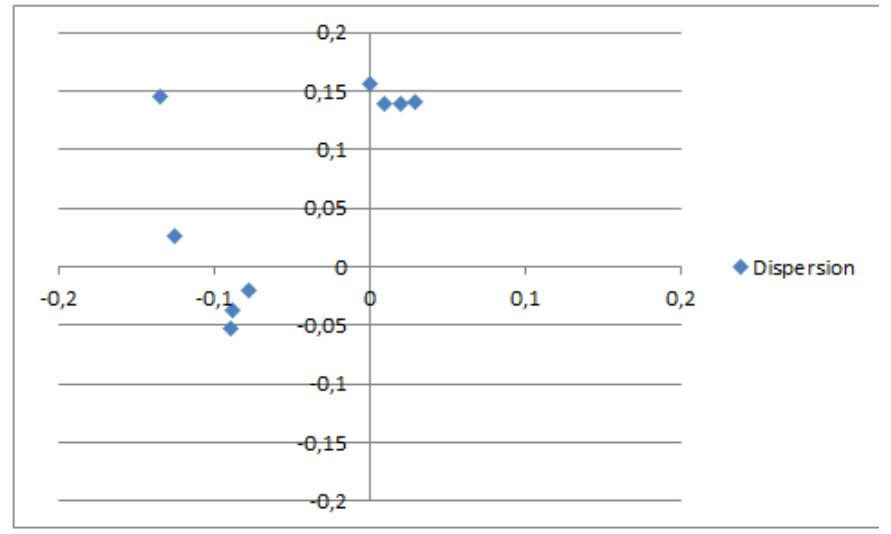

Fig. 9. Representation in the dartboard of the results for the motor with four broken bars.

\section{CONCLUSION}

In the present paper a new method has been proposed to detect rotor asymmetries, such as broken bar, when the motor is fed by a VSD at standstill. The main advantages of this new method are the low computing requirements (no spectral analysis is needed) and the easy interpretation of the results, which are presented in a dart board style: if result of the measurements is a point close to the center of the dartboard, the machine is in health condition. In the case of a rotor asymmetry, the resulting measurement point appears far from the display center. Each time that the test is performed, a new point is added to the display. The proposed algorithm is very simple and has a low computational cost, so that it can be implemented along with the control program of the VSD 
TABLE III

TEST OF THE MOTOR WITH FOUR BROKEN BARS

\begin{tabular}{ccccc}
\hline \hline \multirow{2}{*}{ Degrees } & \multirow{2}{*}{ Voltage $(\mathrm{V})$} & \multicolumn{3}{c}{ Current (A) } \\
& & Test1 & Test2 & Test3 \\
\hline 0 & 115 & 2.55 & 2.57 & 2.65 \\
\hline 30 & 115 & 2.58 & 2.65 & 2.52 \\
\hline 60 & 115 & 2.66 & 2.51 & 2.54 \\
\hline 90 & 115 & 2.53 & 2.55 & 2.62 \\
\hline 120 & 115 & 2.55 & 2.62 & 2.50 \\
\hline 150 & 115 & 2.64 & 2.50 & 2.53 \\
\hline 180 & 115 & 2.50 & 2.52 & 2.61 \\
\hline 210 & 115 & 2.55 & 2.60 & 2.49 \\
\hline 240 & 115 & 2.63 & 2.48 & 2.51 \\
\hline 270 & 115 & 2.51 & 2.52 & 2.60 \\
\hline 300 & 115 & 2.51 & 2.61 & 2.47 \\
\hline 330 & 115 & 2.64 & 2.48 & 2.49 \\
\hline
\end{tabular}

\section{APPENDIX A}

\section{CAge Induction Machine Mounted IN THE LABORATORY TEST BENCH}

Three-phase induction machine, star connection. Rated characteristics: $P=1.5 \mathrm{~kW}, f=50 \mathrm{~Hz}, U=400 \mathrm{~V}, I$ $=3.25 \mathrm{~A}, n=2860$ r.p.m., and $\cos \varphi=0.85$.

\section{REFERENCES}

[1] R. Romero-Troncoso, A. Garcia-Perez, D. Morinigo-Sotelo, O. DuquePerez, R. Osornio-Rios, and M. Ibarra-Manzano, "Rotor unbalance and broken rotor bar detection in inverter-fed induction motors at start-up and steady-state regimes by high-resolution spectral analysis," Electric Power Systems Research, vol. 133, pp. 142 - 148, 2016.

[2] L. Medina, R. de Jesus Romero-Troncoso, E. Cabal-Yepez, J. de Jesus Rangel-Magdaleno, and J. Millan-Almaraz, "FPGA-Based MultipleChannel Vibration Analyzer for Industrial Applications in Induction Motor Failure Detection," IEEE Trans. Instrum. Meas., vol. 59, no. 1, pp. 63-72, Jan 2010.

[3] S. Yin, S. Ding, X. Xie, and H. Luo, "A Review on Basic DataDriven Approaches for Industrial Process Monitoring," IEEE Trans. Ind. Electron., vol. 61, no. 11, pp. 6418-6428, Nov 2014.

[4] S. Choi, B. Akin, M. Rahimian, and H. Toliyat, "Implementation of a Fault-Diagnosis Algorithm for Induction Machines Based on Advanced Digital-Signal-Processing Techniques," IEEE Trans. Indus. Electron., vol. 58, no. 3, pp. 937-948, March 2011.

[5] E. Cabal-Yepez, A. Garcia-Ramirez, R. Romero-Troncoso, A. GarciaPerez, and R. Osornio-Rios, "Reconfigurable Monitoring System for Time-Frequency Analysis on Industrial Equipment Through STFT and DWT," IEEE Trans. Ind. Inf., vol. 9, no. 2, pp. 760-771, May 2013.

[6] J. de Jesus Rangel-Magdaleno, H. Peregrina-Barreto, J. Ramirez-Cortes, P. Gomez-Gil, and R. Morales-Caporal, "FPGA-Based Broken Bars Detection on Induction Motors Under Different Load Using Motor Current Signature Analysis and Mathematical Morphology," IEEE Trans. Instrum. Meas., vol. 63, no. 5, pp. 1032-1040, May 2014.

[7] M. Kang, J. Kim, and J.-M. Kim, "An FPGA-Based Multicore System for Real-Time Bearing Fault Diagnosis Using Ultrasampling Rate AE Signals," IEEE Trans. Ind. Electron., vol. 62, no. 4, pp. 2319-2329, April 2015.

[8] — "High-Performance and Energy-Efficient Fault Diagnosis Using Effective Envelope Analysis and Denoising on a General-Purpose Graphics Processing Unit," IEEE Trans. Power Electron., vol. 30, no. 5, pp. 2763-2776, May 2015.

[9] B. Akin, S. Choi, U. Orguner, and H. Toliyat, "A Simple Real-Time Fault Signature Monitoring Tool for Motor-Drive-Embedded Fault Diagnosis Systems," IEEE Trans. Ind. Electron.,, vol. 58, no. 5, pp. 1990-2001, May 2011.
[10] G. Joksimovic, J. Riger, T. Wolbank, N. Peric, and M. Vasak, "Stator- Current Spectrum Signature of Healthy Cage Rotor Induction Ma- chines," IEEE Trans. Ind. Electron., vol. 60, no. 9, pp. 4025-4033, Sept 2013.

[11] A. Lebaroud and A. Medoued, "Online computational tools dedicated to the detection of induction machine faults," International Journal of Electrical Power \& Energy Systems, vol. 44, no. 1, pp. 752 - 757, 2013.

[12] J. Yun, K. Lee, K. W. Lee, S. B. Lee, and J. Y. Yoo, "Detection and classification of stator turn faults and high-resistance electrical connections for induction machines," IEEE Trans. on Indus. Appl., vol. 45, no. 2, pp. 666-675, March 2009.

[13] G. Stojcić and T. M. Wolbank, "Detecting high-resistance connection asymmetries in inverter fed ac drive systems," in Diagnostics for Electric Machines, Power Electronics and Drives (SDEMPED), 2013 9th IEEE International Symposium on, Aug 2013, pp. 227-232.

Jordi Burriel-Valencia received his Ms.C. degree in Informatic Engineering from the Universitat Politècncia de València, Spain, in 2010. Currently he is a Ph.D. student, working in the Department of Electrical Engineering of the Universitat Politècnica de València, and focuses his research on the development of expert systems for fault diagnosis.

Manuel Pineda-Sanchez (M02) received his M.Sc. degree in 1985 and his Ph.D. degree in 2004 from the Universitat Politècnica de València, both in Electrical Engineering. Currently he is an Associate Professor in the Department of Electrical Engineering of the Universitat Politècnica de València. His research interests include electrical machines and drives, induction motor diagnostics, and numerical simulation of electromagnetic fields.

Juan Perez-Cruz (M09) obtained his M.Sc. degree in 1997 and his Ph.D. degree in 2006 from the Universitat Politècnica de València, both in Electrical Engineering. From 1970 to 1992 he worked in the electrical industry in the field of industrial systems maintenance and automation. In 1992 he joined the Universitat Politècnica de València and is currently Associate Professor of electrical installations and machines. His research interests focus on induction motor diagnostics, numerical modelling, and automation.

Martin Riera-Guasp (M94-SM12) received the M.Sc. degree in Industrial Engineering and the Ph.D. degree in Electrical Engineering from the Universitat Politècnica de València (Spain) in 1981 and 1987, respectively. Currently he is an Associate Professor in the Department of Electrical Engineering of the Universitat Politècnica de València. His research interests include condition monitoring of electrical machines and electrical systems efficiency.

Ruben Puche-Panadero (M09) received his M.Sc. degree in Automatic and Electronic Engineering in 2003, and its Ph.D. degree in Electrical Engineering in 2008, both from the Universitat Politècnica de València. He joined the Universitat Politècnica de València in 2006 and he is currently Associate Professor of Control of Electrical Machines. His research interests focus on induction motor diagnosis, numerical modelling of electrical machines, and advanced automation processes and electrical installations. 